\title{
DESIGUALDADE DE DESEMPENHO E RAÇA: UMA ANÁLISE A PARTIR DO PAEBES 2009
}

ANDREZA CRISTINA MOREIRA DA SILVA BASSO, CAROLINA FERREIRA RODRIGUES, DANIEL AGUIAR DE LEIGHTON BROOKE, DANIEL ARAÚJO VIGNOLI, JULIANA FRIZZONI CANDIAN, WAGNER SILVEIRA REZENDE

\section{RESUMO}

A pesquisa procura demonstrar o papel da raça na explicação de diferenciais de desempenho, avaliado pela proficiência, entre alunos da rede pública do Espírito Santo. Não tem a pretensão de determinar os mecanismos que operam na manutenção dessa desigualdade, mas objetiva enfatizar que raça é uma dimensão importante na compreensão das desigualdades educacionais, responde a diferenças consideráveis de proficiência e deve ser considerada nas tentativas de explicá-las. 


\title{
RESUMEN
}

La investigación procura demostrar el papel de la raza en la explicación de diferenciales de desempeño, evaluado por la competencia, entre alumnos de la red públida de Espírito Santo. No tiene la pretensión de determinar los mecanismos que operan en el mantenimiento de esa desigualdad, pero el objetivo es enfatizar que la raza es una dimensión importante en la comprensión de las desigualdades educativas, responde a diferencias considerables de competencia y debe ser considerada en los intentos por explicarlas.

PALABRAS CLAVE: DESIGUALDADES EDUCATIVAS • RAZA • DE-

SIGUALDAD SOCIAL・RENDIMIENTO ESCOLAR.

\begin{abstract}
This research note seeks to demonstrate the role of race in explaining differences in performance, measured by the proficiency of public school students in the state of Espirito Santo. It is not intended to determine the mechanisms that operate in maitaining this inequality, but aims to emphasize that race is an important dimension in understanding educational differences, being responsible for wide variations in proficiency and therefore should be taken into account in attempts to explain these variations.
\end{abstract}

KEYWORDS: EDUCATIONAL INEQUALITIES • RACE • SOCIAL

DIFFERENCES • LEARNING ACHIEVEMENT. 


\section{INTRODUÇÃO}

A sociedade brasileira é marcada por fortes desigualdades, dentre as quais a desigualdade racial se destaca. A raça é uma dimensão importante da estratificação social, pelo seu caráter adscritivo e por suas implicações nas diversas realizações sociais (alcance educacional, inserção no mercado de trabalho, retornos salariais etc.). Longa tradição de pesquisas (ver, por exemplo, FERNANDES, 1968; HASENBALG, 2005; Hasenbalg, Valle Silva; Lima, 1999; Telles, 2003; Fernandes, 2004; FERES, 2006) tem tratado, com diferentes enfoques, dessas diferenças e de suas consequências, tanto no plano objetivo (escolaridade, renda, mobilidade social) como no plano subjetivo ou simbólico (autoestima, autopercepção enquanto ator social), apontando que o pertencimento a diferentes grupos raciais está fortemente associado a persistentes desigualdades sociais e que, embora seja possível encontrar indivíduos brancos, pretos e pardos em quaisquer pontos da escala de estratificação, não-brancos estão sempre em piores condições que brancos em todos os indicadores sociais (REIS ET AL., 2007).

No entanto, nos estudos das desigualdades educacionais, no que toca às diferenças de domínio de conteúdos cognitivos 
que a escola tem por função transmitir aos seus alunos, a questão das desigualdades raciais aparece pouco. São raros os estudos que se dedicam a investigar como diferenças raciais impactam de forma diferenciada o desempenho escolar ${ }^{1}$. Essa nota de pesquisa não pretende preencher uma lacuna de investigações desse tema central para a estruturação e reprodução das desigualdades sociais no Brasil, mas apenas apontar a importância do problema a partir dos resultados de avaliação em larga escala realizada em um sistema da rede estadual de educação no Brasil. O objeto é destacar, de forma descritiva e simples, como as desigualdades de desempenho estão associadas a diferenças raciais.

Vale enfatizar que a perspectiva que subjaz ao trabalho é a de que bons resultados escolares estão associados a melhores chances de vida e, uma vez que a escola pode ser pensada como instrumento de superação das desigualdades sociais, mesmo que de forma não absoluta, a compreensão de por que os não-brancos têm, sistematicamente, experimentado situações escolares desfavoráveis, em relação aos domínios dos conteúdos, pode contribuir para reflexões mais substanciais da aplicação e eficácia de políticas públicas que buscam alterar esse cenário de desigualdade.

$O$ trabalho se divide em três partes, além desta pequena introdução. A seguir, discutiremos as relações entre raça e desigualdades escolares. Na terceira parte, serão apresentados os resultados da avaliação em larga escala que consideramos na demonstração das desigualdades entre brancos e outros grupos de cor no sistema público de educação. E, por fim, tecemos algumas considerações finais.

\section{DESIGUALDADES RACIAIS E EDUCAÇÃO}

Considerada em uma acepção mais ampla, a educação tem objetivos que ultrapassam a ação da escola: preparação para o mundo do trabalho e para a vida em sociedade. À escola e ao sistema escolar cabem, estritamente, oferecer oportunidades para a aquisição de competências cognitivas que possibilitem o alcance de tais prerrogativas. Em sua acepção mais específica, portanto, a educação, no plano do estabelecimento escolar, equivale à instrução. No Brasil, a escola ainda é um bem desigualmente

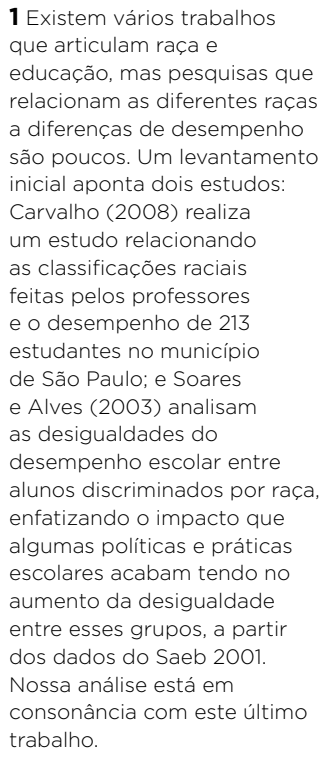


distribuído e desigualdades educacionais estão marcadas por filtros socioeconômicos, raciais, territoriais. Especialmente no caso de uma sociedade tão desigual quanto o Brasil, grande parte da variação no desempenho escolar está associada às condições socioeconômicas e às características da família (...).

Na década de 1990, o Brasil concluiu, com considerável êxito, o processo de universalização da educação básica: quase a totalidade das crianças entre 7 e 14 anos frequenta a escola, embora ainda haja grande variação entre as regiões brasileiras, como mostra a tabela abaixo. Do ponto de vista formal, portanto, a igualdade de acesso foi amplamente instalada.

TABELA 1 - Média, por região, do acesso à escola - 7 a 14 anos

\begin{tabular}{l|cc}
\hline REGIÃO & 1991 & 2000 \\
\hline Norte & 68,10 & 83,57 \\
Nordeste & 65,33 & 87,85 \\
Sudeste & 85,43 & 93,07 \\
Sul & 85,58 & 94,83 \\
Centro-Oeste & 82,05 & 91,47 \\
\hline
\end{tabular}

Fonte: Atlas do Desenvolvimento Humano no Brasil.

A observação da tabela acima aponta que, nas regiões Norte e Nordeste, o acesso à escola está bastante aquém do registrado nas demais regiões. Considerando que, nessas regiões, é maior o percentual de não-brancos que no restante do Brasil, como mostra a tabela 2 abaixo, já se tem um indício do acesso desigual à escola no que diz respeito às raças.

TABELA 2 - População residente, por grandes regiões e por raça

\begin{tabular}{l|rrr:r|r|r|r}
\hline COR/RACA & TOTAL & NORTE & NORDESTE & SUDESTE & SUL & $\begin{array}{c}\text { CENTRO- } \\
\text { OESTE }\end{array}$ \\
\hline Branca & 48,4 & 22,9 & 29,3 & 56,8 & 78,7 & 42,2 \\
Preta & 6,8 & 5,1 & 7,9 & 7,7 & 3,5 & 6,5 \\
Parda & 43,8 & 71,0 & 62,2 & 34,4 & 17,0 & 50,2 \\
Outra & 0,9 & 1,0 & 0,6 & 1,0 & 0,8 & 1,0 \\
\hline
\end{tabular}

Fonte: Atlas do Desenvolvimento Humano no Brasil.

Com efeito, Fernandes (2004), observando o impacto dos determinantes do alcance educacional no Brasil ao longo 
de 81 anos, encontrou que a raça é o único determinante da estratificação educacional que não decresce no período, o que significa que "a população não-branca enfrenta barreiras altas nos primeiros níveis de instrução, como, por exemplo, o simples acesso à educação e depois barreiras crescentemente altas para ter acesso a níveis educacionais superiores.” (op. cit., p. 52).

Políticas universalistas, como a de inclusão em massa ao sistema de ensino, tendem a diminuir a desigualdade em geral no Brasil. No entanto, na concepção dessas políticas está a ideia de que todas as pessoas menos favorecidas, independentemente da cor da pele, serão ajudadas de forma igual, o que, de modo geral, não acontece. Grupos diferentes se apropriam de forma diferente das políticas. "Políticas universalistas não previnem o racismo e a discriminação racial e continuarão a separar brancos, pretos e pardos na estrutura de classes. Os negros são desproporcionalmente ignorados por tais políticas, que nunca são verdadeiramente universais." (Telles, op. CIT., P. 307). Ou seja, para que políticas voltadas para a educação possam, de fato, gerar efeitos positivos sobre as desigualdades no cenário escolar, é necessário que elas conheçam o problema, de modo a combatê-lo de maneira efetiva. Além disso, são fundamentais esforços de conscientização racial que sejam capazes de superar as situações de discriminação.

Além das diferenças de acesso e das barreiras à promoção dentro do sistema escolar, outro aspecto em que a desigualdade entre brancos e não-brancos deve receber atenção diz respeito ao domínio de conteúdos cognitivos que a escola tem por função transmitir aos seus alunos. Embora a escola assuma cada vez mais funções relativas à família ou às comunidades, a grande expectativa social em relação a ela, especialmente da família, está relacionada à aprendizagem. Nesse aspecto é que se concentra boa parte dos estudos sobre educação e vários esforços são feitos com o objetivo de avaliar o alcance desse domínio. Os sistemas de avaliações nacionais como o Saeb (Sistema Nacional de Avaliação da Educação Básica) - exame nacional aplicado a uma amostra de turmas de $4^{\mathrm{a}}$ e $8^{\mathrm{a}}$ séries do Ensino Fundamental e do $3^{\circ}$ ano do Ensino Médio de escolas em todo país a cada dois anos - e a Prova Brasil - também realizada a cada dois anos, com todos os alunos de área urbana de $4^{\mathrm{a}}$ e $8^{\mathrm{a}}$ séries do ensino fundamental 
e com uma amostra de alunos do $3^{\circ}$ ano do Ensino Médio - e as inúmeras avaliações de âmbito estadual - como, por exemplo, o Saresp, do Estado de São Paulo; o Simave, em Minas Gerais; o Paebes do Espírito Santo; entre vários outros - são iniciativas que refletem a preocupação com a avaliação e a melhoria da qualidade do ensino no país. E é a esse domínio que diz respeito esta nota de pesquisa. Nosso objetivo é mostrar como a raça está associada a desigualdades de desempenho entre alunos do sistema público brasileiro, mesmo quando as características familiares, medidas pela condição socioeconômica, são controladas.

Antes de passarmos aos resultados encontrados, convém considerar o que entendemos por raça, que é algo inexistente no plano biológio, não existam diferentes "raças humanas", mas que, no plano social, é um conceito com clara relevância. Como afirma Guimarães (2005, p. 61):

Raças são construtos sociais, formas de identidade basea-

das numa ideia biológica errônea, mas socialmente eficaz para construir, manter e reproduzir diferenças e privilégios. Se as raças não existem num sentido estrito e realista de ciência, ou seja, se não são um fato do mundo físico, elas existem, contudo, de modo pleno, no mundo social, produtos e formas de classificação que orientam as ações humanas.

No Brasil, ao contrário do que acontece na grande maioria dos países multirraciais, os conflitos raciais são delimitados e não pesam sobre a participação eleitoral ou liberdade de expressão, concentrando-se na igualdade de oportunidade e acesso a bens e serviços (Guimarães, 2010). Por isso, o desafio das pesquisas sobre as relações raciais no Brasil está em não importar as categorias de raça/cor ou cultura, mas se indagar sobre como e por que o Brasil criou essa forma particular de sociedade multirracial (SKIDMORE, 2002), que se crê altamente mestiça e culturalmente homogênea, mas que se recria continuamente em preto e branco (GUIMARÃES, OP. CIT.).

No contexto brasileiro, a noção de cor é mais comumente mobilizada que a noção de raça como categoria de classificação. É através da cor que a raça aparece como marcador primordial do destinos dos negros brasileiros (GUIMARÃEs, 2010, 
P. 124). Segundo Telles (2003), a ideia de cor capta melhor a fluidez e ambiguidade das relações raciais no Brasil. Essa noção, no entanto, equivale ao conceito de raça, pois está associada à produção de hierarquias entre pessoas de cores diferentes, ou seja, independentemente do conceito, de raça ou cor, as pessoas são racializadas e socialmente categorizadas. Portanto, a raça tem papel importante na atribuição de sentido à ação social e não se pode negar a existência de certa gramática social que atribui ao grupo negro uma série de valores socialmente negativos, comprometendo a autoestima, a autoconfiança e a autopercepção dos negros enquanto atores social e politicamente relevantes (REIS ET AL., OP. CIT., P. 7).

A gramática social que hierarquiza socialmente as pessoas por sua cor é codificada por regras informais de interação social, o que garante um aspecto de naturalidade aos direitos e privilégios garantidos aos que ocupam as posições mais altas (Telles, P. 309).

\section{RESULTADOS - DESIGUALDADES RACIAIS NO PAEBES 2009}

Os resultados apresentados aqui foram elaborados a partir dos dados do Programa de Avaliação da Educação Básica do Espírito Santo, o Paebes, edição de 2009. O objetivo da análise é comparar o desempenho dos alunos nesse programa, considerando as etapas avaliadas, $4^{\mathrm{a}}$ série $/ 5^{\circ}$ ano, $8^{\mathrm{a}}$ série $/ 9^{\circ}$ ano do Ensino Fundamental e $1^{\circ}$ ano do Ensino Médio, levando em conta o índice socioeconômico dos alunos e a raça autodeclarada. A escolha desse programa se deve a três razões: primeiro, pelo fácil acesso que teríamos aos dados; segundo, porque se trata de um programa consistente, que existe com alguma regularidade desde 2000; e, terceiro, porque o Espírito Santo seria um estado representativo do Sudeste, no que diz respeito à composição racial.

A raça dos alunos considerada nessa análise é um item do instrumento aplicado aos alunos das séries consideradas e as opções de resposta disponíveis eram branco, pardo, negro, amarelo e indígena. A classificação utilizada pelo IBGE, vale ressaltar, considera as categorias: branco, pardo, preto, ama- 
2 Não tivemos acesso aos dados da PNAD para comparar a composição racial do estado do Espírito Santo com a dos alunos participante do Paebes, mas considerando a distribuição por regiões, parece que autoreconhecimento como sendo pardo ou negro é mais expressivo entre os alunos que entre a população. relo e indígena; razão pela qual as comparações diretas entre os resultados devem ser evitadas, embora estes possam ser aproximados. Por representarem um grupo muito pequeno, a análise excluiu os alunos que se autodeclararam amarelos e indígenas. Dessa forma, foram considerados cerca de $95 \mathrm{mil}$ alunos da rede pública de ensino do Espírito Santo, distribuídos por raça conforme mostra a tabela 3 abaixo. Como se pode observar, o percentual de alunos que se declarou pardo ou negro na rede pública do Espírito Santo é bem maior que o percentual observado a partir da PNAD 2009².

TABELA 3 - Percentual de alunos, por raça/cor

\begin{tabular}{l|c|c}
\hline REGIÃO & 1991 & 2000 \\
\hline Branca & 28.694 & 30,1 \\
Parda & 51.170 & 53,7 \\
Negra & 15.502 & 16,3 \\
Total & 95.366 & 100,1 \\
\hline
\end{tabular}

Fonte: Paebes 2009 - tabulação própria.

A tabela 4 a seguir mostra o desempenho médio de acordo com a raça dos alunos para cada série considerada. Como é possível observar, os alunos que se declararam negros têm, em média, os piores desempenhos em todas as séries e nas duas disciplinas consideradas, seguidos pelos alunos pardos e, por fim, os alunos brancos, que têm médias acima das médias do estado. 
TABELA 4 - Proficiência dos alunos por raça/cor e ano/série

\begin{tabular}{|c|c|c|c|c|c|}
\hline COR/RAÇA & SÉRIE/ANO & DISCIPLINA & $\begin{array}{l}\text { NÚMERO DE } \\
\text { ALUNOS }\end{array}$ & $\begin{array}{c}\text { MÉDIA DE } \\
\text { PROFICIÊNCIA }\end{array}$ & $\begin{array}{l}\text { DESVIO } \\
\text { PADRÃO }\end{array}$ \\
\hline \multirow{6}{*}{ Branca } & \multirow[t]{2}{*}{$5^{\circ}$ ano $E F$} & $\begin{array}{l}\text { Língua } \\
\text { Portuguesa }\end{array}$ & 11.351 & 195,2 & 39,5 \\
\hline & & Matemática & 11.351 & 199,4 & 47,9 \\
\hline & \multirow{2}{*}{$9^{\circ}$ ano EF } & $\begin{array}{l}\text { Língua } \\
\text { Portuguesa }\end{array}$ & 8.696 & 243,1 & 43,2 \\
\hline & & Matemática & 8.696 & 253,1 & 49,8 \\
\hline & \multirow[t]{2}{*}{$1^{\circ}$ ano $E M$} & $\begin{array}{l}\text { Língua } \\
\text { Portuguesa }\end{array}$ & 8.647 & 248,5 & 44,7 \\
\hline & & Matemática & 8.647 & 260,8 & 49,5 \\
\hline \multirow{6}{*}{ Parda } & \multirow{2}{*}{$5^{\circ}$ ano EF } & $\begin{array}{l}\text { Língua } \\
\text { Portuguesa }\end{array}$ & 20.568 & 192,8 & 37,2 \\
\hline & & Matemática & 20.568 & 194,9 & 45,0 \\
\hline & \multirow{2}{*}{$9^{\circ}$ ano EF } & $\begin{array}{l}\text { Língua } \\
\text { Portuguesa }\end{array}$ & 15.447 & 235,5 & 41,2 \\
\hline & & Matemática & 15.447 & 240,3 & 45,8 \\
\hline & \multirow{2}{*}{$1^{\circ}$ ano EM } & $\begin{array}{l}\text { Língua } \\
\text { Portuguesa }\end{array}$ & 15.155 & 240,0 & 42,6 \\
\hline & & Matemática & 15.155 & 247,0 & 46,2 \\
\hline \multirow{6}{*}{ Negra } & \multirow{2}{*}{$5^{\circ}$ ano EF } & $\begin{array}{l}\text { Língua } \\
\text { Portuguesa }\end{array}$ & 6.434 & 183,7 & 35,0 \\
\hline & & Matemática & 6.434 & 182,3 & 41,5 \\
\hline & \multirow[t]{2}{*}{$9^{\circ}$ ano EF } & $\begin{array}{l}\text { Língua } \\
\text { Portuguesa }\end{array}$ & 4.091 & 227,9 & 40,6 \\
\hline & & Matemática & 4.091 & 230,9 & 44,5 \\
\hline & \multirow{2}{*}{$1^{\circ}$ ano $E M$} & $\begin{array}{l}\text { Língua } \\
\text { Portuguesa }\end{array}$ & 4.977 & 235,4 & 42,4 \\
\hline & & Matemática & 4.977 & 242,0 & 45,0 \\
\hline \multirow{6}{*}{ Total } & \multirow{2}{*}{$5^{\circ}$ ano EF } & $\begin{array}{l}\text { Lingua } \\
\text { Portuguesa }\end{array}$ & 38.353 & 192,0 & 37,7 \\
\hline & & Matemática & 38.353 & 194,1 & 45,7 \\
\hline & \multirow{2}{*}{$9^{\circ}$ ano EF } & $\begin{array}{l}\text { Língua } \\
\text { Portuguesa }\end{array}$ & 28.234 & 236,8 & 42,0 \\
\hline & & Matemática & 28.234 & 242,9 & 47,5 \\
\hline & \multirow{2}{*}{$1^{\circ}$ ano EM } & $\begin{array}{l}\text { Lingua } \\
\text { Portuguesa }\end{array}$ & 28.779 & 241,8 & 43,4 \\
\hline & & Matemática & 28.779 & 250,3 & 47,5 \\
\hline
\end{tabular}

Fonte: Paebes 2009 - tabulação própria.

Mas para considerar de forma mais adequada a variação do desempenho em uma sociedade desigual como a brasileira, é preciso levar em conta a condição socioeconômica dos alunos. Para operacionalizá-la, nesse trabalho, foram consideradas variáveis referentes à posse de bens e a escolaridade dos pais conforme informadas pelos alunos, variáveis que influenciam 
3 A distribuicão das medidas do ISE estendia-se até quatro desvios padrão acima e abaixo da média. Entretanto, como o quantitativo de alunos que ocupavam o quarto desvio padrão, nas duas extremidades da curva era muito pequeno, os alunos que distavam três e quatro desvios padrões da média foram agregados em uma única categoria. A medida de ISE categorizada por desvio padrão contabilizou então os alunos que distavam um, dois, e três ou mais desvios padrões a vida social e escolar do aluno. A escolaridade dos pais é um fator muito influente na medida do desempenho. Ela está relacionada com as atitudes que os pais tomam e influenciam o desenvolvimento de comportamentos e atitudes dos filhos.

A escolaridade dos pais se vincula ao consumo cultural que os filhos podem desenvolver, ao hábito de leitura, à disciplina e ao comportamento dentro e fora de sala de aula, ao contato recente com tecnologias e recursos educacionais diferenciados, entre outros fatores. Além disso, tal escolaridade está ligada também ao comportamento dos pais diante da escolaridade dos filhos, como a exigência de dedicação e comprometimento com a escola, o incentivo à leitura, o acompanhamento dos deveres de casa, a ajuda com as dúvidas que o filho tem com as lições, e outros elementos. Assim, em teoria, o aumento da escolaridade dos pais tende a se refletir na melhoria do desempenho de seus filhos.

A posse de bens materiais é tratada como indicativa de situações e condições sociais específicas que, por sua vez, impactam no desempenho dos estudantes. A posse de bens como aparelhos de televisão, geladeira, automóvel, e a presença, em casa, de banheiro, indicativo de acesso a uma forma mínina de saneamento, são elementos que podem influenciar e, de modo geral, influenciam, no desempenho dos alunos. A presença desses bens, como se pode imaginar, não interfere diretamente no desempenho do aluno em sala de aula, ou seja, o fato de o aluno ter geladeira em casa não significa que ele, por conta disso, terá um desempenho melhor em matemática, por exemplo, ou que aprenda melhor do que aqueles que não têm. No entanto, a presença desses fatores é indicativa da condição social e econômica do aluno e de sua família.

Para fins de análise, o índice socioeconômico foi categorizado em termos dos desvios padrão da distribuição ${ }^{3}$ e os resultados serão apresentados para 6 (seis) categorias do índice. Na tabela 5 abaixo, apresentamos a distribuição percentual dos alunos pelas raças consideradas e em cada categoria do índice socioeconômico. A distribuição percentual dos grupos raciais nas categorias do índice socioeconômico é semelhante, estando o maior percentual de brancos, pardos e negros nas categorias intermediárias. Por outro lado, as categorias de maior índice socioeconômico têm maior participação de brancos que as demais, ocorrendo o contrário com os grupos pardo e negro, que 
diminuem sua participação ao longo das categorias do índice socioeconômico, o que reforça que a condição socioeconômica é diferenciada segundo os grupos raciais. A composição desses grupos é diferenciada segundo as raças, uma evidência da desigualdade de alocação de recursos.

TABELA 5 - Distribuição dos alunos por categorias

\begin{tabular}{|c|c|c|c|c|c|c|c|c|}
\hline \multirow{2}{*}{ Cor/raça } & \multirow{2}{*}{$\begin{array}{l}\text { NÚMERO E } \\
\text { PERCENTUAL DE } \\
\text { ALUNOS }\end{array}$} & \multicolumn{6}{|c|}{ CATEGORIAS } & \multirow{2}{*}{ Total } \\
\hline & & -3 & -2 & -1 & 1 & 2 & 3 & \\
\hline Branca & $\begin{array}{l}\text { Número de alunos } \\
\text { Percentual na raça } \\
\text { Percentual no ISE }\end{array}$ & $\begin{array}{r}402 \\
1,4 \\
23,9\end{array}$ & $\begin{array}{r}3.513 \\
12,3 \\
27,6\end{array}$ & $\begin{array}{l}9591 \\
33,5 \\
27,5\end{array}$ & $\begin{array}{l}9.412 \\
32,8 \\
30,6\end{array}$ & $\begin{array}{r}4.702 \\
16,4 \\
37,1\end{array}$ & $\begin{array}{r}1.049 \\
3,7 \\
41,1\end{array}$ & $\begin{array}{r}28.669 \\
100,0 \\
30,1\end{array}$ \\
\hline Parda & $\begin{array}{l}\text { Número de alunos } \\
\text { Percentual na raça } \\
\text { Percentual no ISE }\end{array}$ & $\begin{array}{r}909 \\
1,8 \\
53,9\end{array}$ & $\begin{array}{r}6.869 \\
13,4 \\
54,0\end{array}$ & $\begin{array}{r}19.186 \\
37,5 \\
55,0\end{array}$ & $\begin{array}{r}16.597 \\
32,5 \\
54,0\end{array}$ & $\begin{array}{r}6.358 \\
12,4 \\
50,1\end{array}$ & $\begin{array}{r}1.199 \\
2,3 \\
46,9\end{array}$ & $\begin{array}{r}5.1118 \\
100,0 \\
53,7\end{array}$ \\
\hline Negra & $\begin{array}{l}\text { Número de alunos } \\
\text { Percentual na raça } \\
\text { Percentual no ISE }\end{array}$ & $\begin{array}{r}374 \\
2,4 \\
22,2\end{array}$ & $\begin{array}{r}2.331 \\
15,1 \\
18,3\end{array}$ & $\begin{array}{r}6.127 \\
39,6 \\
17,6\end{array}$ & $\begin{array}{r}4.716 \\
30,5 \\
15,3\end{array}$ & $\begin{array}{r}1.626 \\
10,5 \\
12,8\end{array}$ & \begin{tabular}{r|}
306 \\
2,0 \\
12,0
\end{tabular} & $\begin{array}{r}15.480 \\
100,0 \\
16,2\end{array}$ \\
\hline Total & $\begin{array}{l}\text { Número de alunos } \\
\text { Percentual na raça } \\
\text { Percentual no ISE }\end{array}$ & $\begin{array}{r}1.685 \\
1,8 \\
100,0\end{array}$ & \begin{tabular}{r|}
12.713 \\
13,3 \\
100,0
\end{tabular} & $\begin{array}{r}34.904 \\
36,6 \\
100,0\end{array}$ & $\begin{array}{r}30.725 \\
32,3 \\
100\end{array}$ & $\begin{array}{r}12.686 \\
13,3 \\
100,0\end{array}$ & $\begin{array}{r}2.554 \\
2,7 \\
100,0\end{array}$ & $\begin{array}{r}95.267 \\
100,0 \\
100,0\end{array}$ \\
\hline
\end{tabular}

Fonte: Paebes 2009 - tabulação própria.

Os gráficos 1 a 6 apresentam as diferenças de desempenho para os grupos raciais nas disciplinas e séries avaliadas no Paebes 2009. O que se pode observar é que, tanto em Língua Portuguesa quanto em Matemática e em qualquer uma das séries avaliadas, o desempenho médio dos alunos que se declararam negros é inferior ao desempenho dos alunos que se declararam pardo, e esses últimos têm pior desempenho que os alunos que se declararam brancos. A vantagem dos brancos em relação aos demais grupos aumenta com o índice socioeconômico, o que é esperado a partir de outras pesquisas. Soares e Alves (2003) encontraram que “o impacto da posição social na proficiência dos alunos brancos é bem maior do que para os alunos negros, ficando os alunos pardos numa situação intermediária. Entre os alunos com posição social mais baixa, a diferença entre os três grupos é mínima, enquanto nas posições mais privilegiadas o grau de proficiência entre eles se diferencia bastante" (op. cit., p. 154).

O que chama atenção é a magnitude dessa diferença na proficiência entre os dois grupos, que é de 22 pontos em Língua Portuguesa e em Matemática no $1^{\circ}$ ano do Ensino Médio, e chega a ser maior que 25 pontos no $9^{\circ}$ ano do Ensino Fundamental. 
GRÁFICO 1 - Proficiência média dos grupos raciais por índice socioeconômico $-5^{\circ}$ ano do Ensino Fundamental - Língua Portuguesa

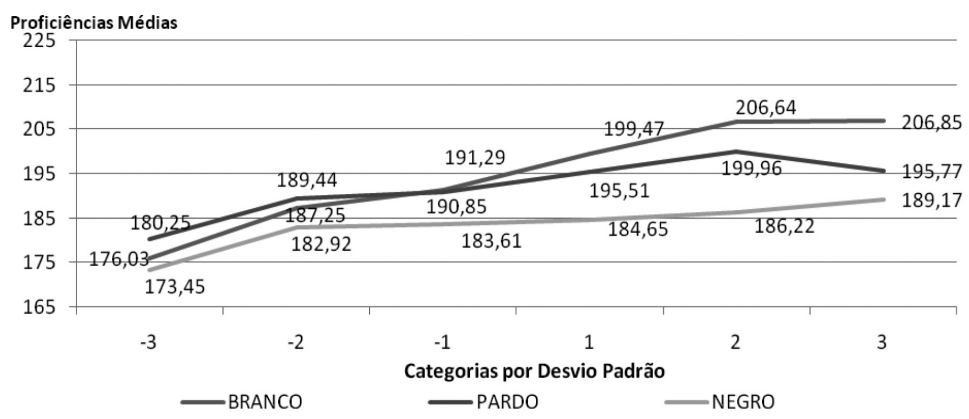

Fonte: Paebes 2009 - tabulação própria.

GRÁFICO 2 - Proficiência média dos grupos raciais por índice socioeconômico $-5^{\circ}$ ano do Ensino Fundamental - Matemática

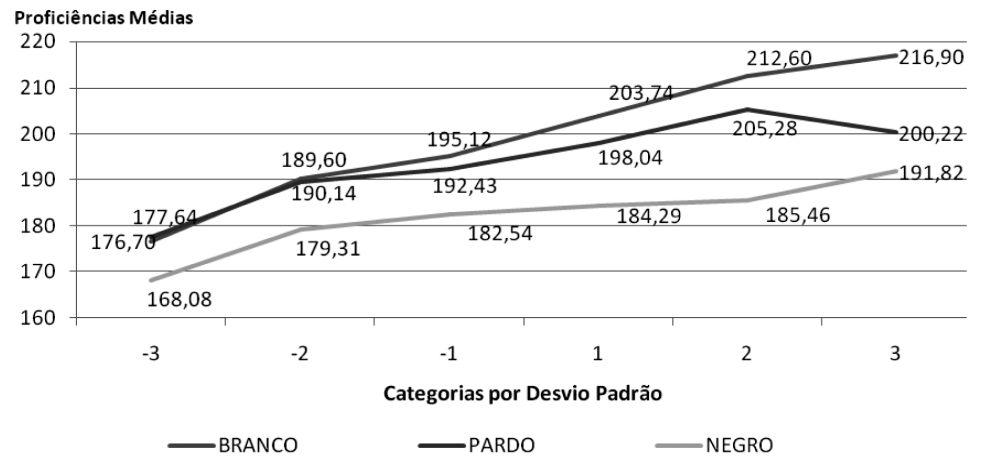

Fonte: Paebes 2009 - tabulação própria.

Gráfico 3 - Proficiência média dos grupos raciais por índice socioeconômico $-9^{\circ}$ ano do Ensino Fundamental - Língua Portuguesa
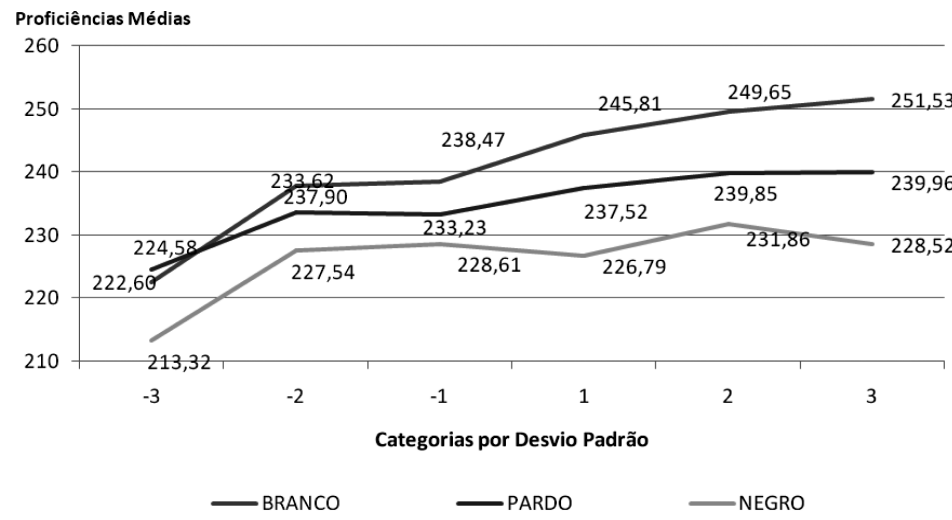
GRÁFICO 4 - Proficiência média dos grupos raciais por índice socioeconômico $-9^{\circ}$ ano do Ensino Fundamental - Matemática

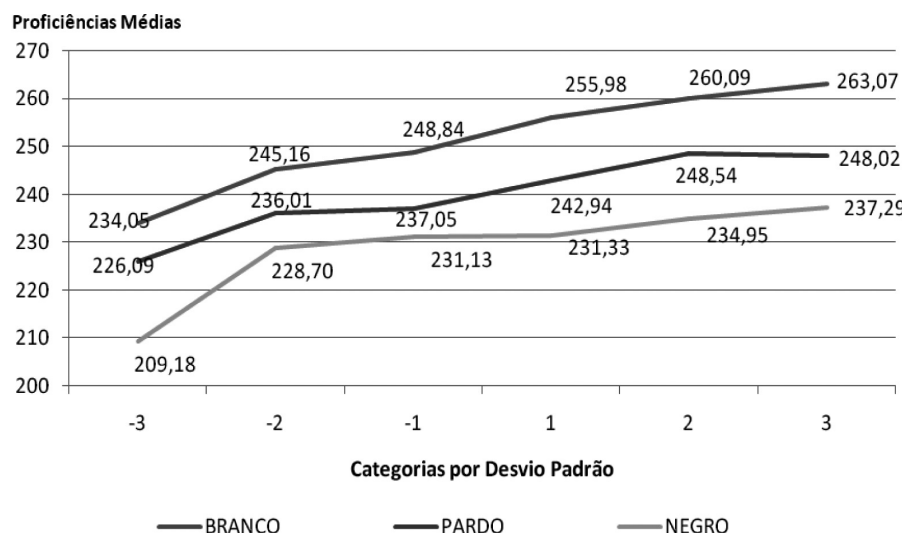

Fonte: Paebes 2009 - tabulação própria.

Gráfico 5 - Proficiência média dos grupos raciais por índice socioeconômico - $1^{\circ}$ ano do Ensino Médio - Língua Portuguesa

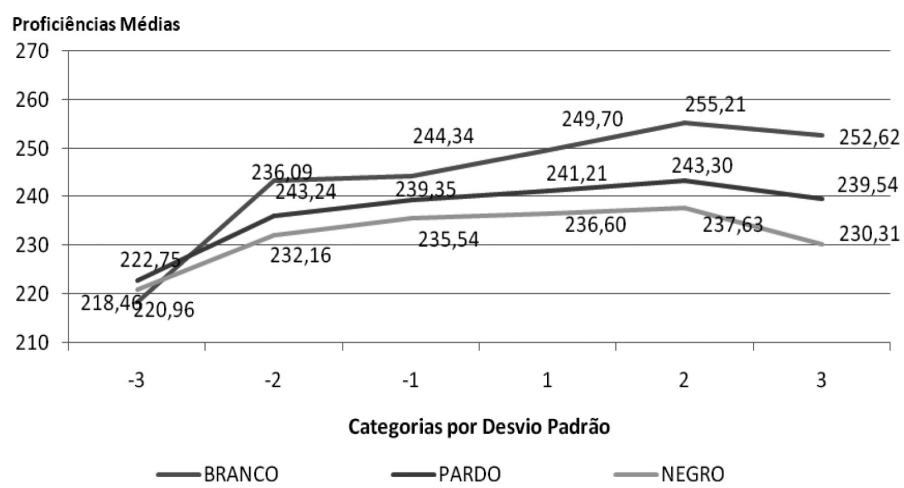

Fonte: Paebes 2009 - tabulação própria.

Gráfico 6 - Proficiência média dos grupos raciais por índice socioeconômico - $1^{\circ}$ ano do Ensino Médio - Matemática

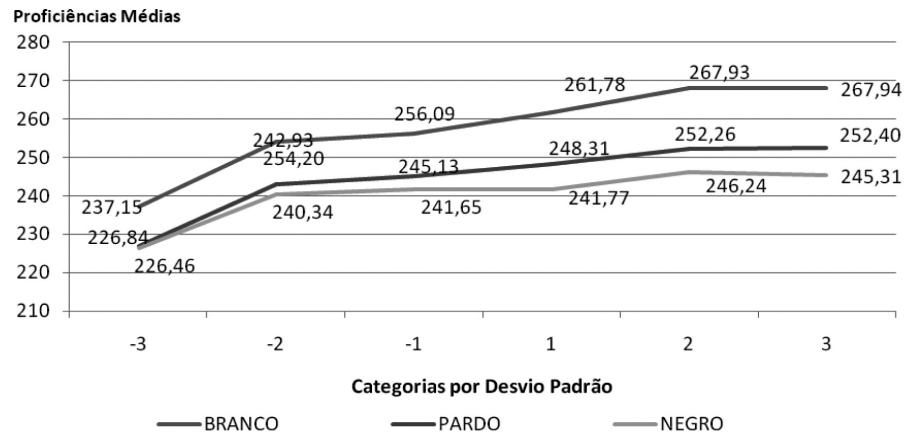


Outras características dos alunos, como idade e sexo, e características dos professores e das escolas (qualificação, raça, infraestrutura da escola) precisam ser consideradas para uma apreciação mais completa e adequada dos diferenciais de raça sobre o desempenho indicado pela proficiência dos alunos. No entanto, o que buscamos demonstrar aqui é que esse efeito dos diferentes grupos raciais não é aleatório e nem é o que sobra quando se controla outras características dos alunos. Raça é uma dimensão importante na compreensão das desigualdades educacionais, responde a diferenças consideráveis de proficiência e deve ser considerada nas tentativas de explicá-las.

\section{CONSIDERAÇÕES FINAIS}

Essa nota de pesquisa procurou destacar a raça como variável relevante na explicação dos diferencias de desempenho escolar, medidos pela proficiência, no Paebes, o programa de avaliação das escolas públicas do Espírito Santo. O que observamos é que a raça tem efeito considerável e significativo, diferenciado de acordo com a condição socioeconômica. Esses resultados não pretenderam, e nem dão conta de esclarecer sobre os mecanismos que levam as esses resultados diferenciados.

É possível levantar uma série de fatores que explicam a diferença. Telles (2003) aponta que:

\footnotetext{
Para a maioria das crianças, que frequentam as escolas públicas brasileiras, as desigualdades são reforçadas por professores e funcionários que se dedicam mais aos brancos, quem eles acreditam que tem mais chance de sucesso, que gera, entre os negros, baixa autoestima e menor capital humano. O contexto de comportamento social racista alimenta o mecanismo que perpetua a desigualdade racial. (p. 316)
}

Ou seja, o fato de que as desigualdades já existentes na sociedade seriam reforçadas pelos professores, desacreditando os próprios alunos de suas capacidades pode ser uma explicação para a diferença entre os desempenhos observados entre os grupos raciais. É uma hipótese que precisa ser testada. Os próximos passos da pesquisa em curso deverão dedicar-se, portanto, a testar conjecturas acerca desses resultados, com vistas 


\section{ao desenvolvimento de uma agenda de pesquisa acerca de raça e desigualdades educacionais no Brasil.}

\section{REFERÊNCIAS BIBLIOGRÁFICAS}

CARVALHO, Marília. “Quem é negro, quem é branco: desempenho escolar e classificação racial de alunos”. Revista Brasileira de Educação, n. 28, 2008.

FERES Jr., João. Aspectos semânticos da discriminação racial no Brasil: para além da teoria da modernidade. Revista Brasileira de Ciências Sociais, n. 61, p. $163-176,2006$.

FERNANDES, Danielle C. Estratificação educacional, origem socioeconômica e raça no Brasil: as barreiras da cor. Concurso de monografias: Prêmio IPEA 40 anos. IPEA - CAIXA, 2004.

FERNANDES, Florestan. Mobilidade social e relações raciais: o drama do negro e do mulato numa sociedade em mudança. Cadernos Brasileiros, n. 47, p. $51-67,1968$.

FIGUEIREDO SANTOS, José A. Efeitos de classe na desigualdade racial no Brasil. Dados - Revista de Ciências Sociais, n. 1, v. 48, p. 21-65, 2005.

GUIMARÃES, Antônio Sérgio A. Raça e os estudos de relações raciais no Brasil. Novos Estudos Cebrap, n. 54, p. 147-56, 1999.

Racismo e Anti-racismo no Brasil. São Paulo: FUSP; Editora 34, 2005.

Editora 34, 2002.

Raça e pobreza no Brasil. Classes, raça e democracia. São Paulo:

. Sociologia e desigualdades: abordagens e desafios. In: MARTINS, Carlos B., MARTINS, Heloísa H. T. de Souza (Coord.). Horizontes das Ciências Sociais no Brasil - Sociologia. São Paulo: ANPOCS, 2010.

HASENBALG, Carlos. Discriminação e desigualdades raciais no Brasil. Belo Horizonte: Editora UFMG, 2005.

HASENBALG, Carlos; VALLE SILVA, Nelson; LIMA, Márcia. Cor e estratificação social. Rio de Janeiro: Contra Capa, 1999.

REIS, Bruno P. W. et al. Raça, recursos e desigualdade política em Belo Horizonte, Grupo de Trabalho: Democracia e desigualdades sociais. Recife: XIII Encontro da Sociedade Brasileira de Sociologia, 2007.

SKIDMORE, Thomas E. Raça e classe no Brasil: perspectiva histórica. O Brasil visto de fora. São Paulo: Editora Paz e Terra, 2001.

SOARES, José Francisco, ALVES, Maria Teresa G. Desigualdades raciais no sistema brasileiro de educação básica. Educação e Pesquisa, n. 29, v. 1, p. 147-165, 2003.

TELLES, Edward. Racismo à brasileira. Rio de Janeiro: Relume Dumará; Ford Foundation, 2003. 


\section{ANDREZA CRISTINA MOREIRA DA SILVA BASSO}

Licenciada em Ciências Sociais pela UFJF, Estagiária da Coordenação de Análise e Divulgação de Resultados/CAEd andreza_basso@hotmail.com

\section{CAROLINA FERREIRA RODRIGUES}

Graduanda em Estatística pela UFJF, Estagiária da Coordenação de Análise e Divulgação de Resultados/CAEd carolina.adm@gmail.com

\section{DANIEL AGUIAR DE LEIGHTON BROOKE}

Graduado em Ciências Socias pela UFMG, Analista de Avaliação da Coordenação de Análise e Divulgação de Resultados/CAEd dbrooke@caed.ufrj.br

\section{DANIEL ARAÚJO VIGNOLI}

Psicólogo pela UFJF, Analista de Instrumentos de Avaliação da Coordenação de Análise e Divulgação de Resultados/CAEd vignoli@caed.ufrj.br

\section{JULIANA FRIZZONI CANDIAN}

Doutoranda em sociologia pelo IESP - UERJ, Analista de Avaliação da Coordenação de Análise e Divulgação de Resultados/CAEd jfcandian@gmail.com

\section{WAGNER SILVEIRA REZENDE}

Doutorando em Ciências Sociais pela UFJF, Coordenador de Análise e Divulgação de Resultados/CAEd wsr_ufrj@yahoo.com.br 